\title{
A Comparitive Study of Outcome of Septoplasty for Nasal Obstruction with and Without Hypertrophied Inferior Turbinate Reduction
}

\author{
Reena Vare ${ }^{1}$, Rajendra Bohra ${ }^{2}$, Ashfaque Ansari ${ }^{3}$, Arjun Antony ${ }^{4}$ \\ Affiliated To Mahatma Gandhi Mission (MGM) Medical College \& Hospital, Aurangabad, India
}

\begin{abstract}
:
Aims: To know whether reduction of hypertrophied Inferior turbinate in addition to Septoplasty improves outcome of nasal obstruction in patients with deviated nasal septum with inferior turbinate hypertrophy.

Methods: 30 patients with septal deviation and contralateral inferior turbinate hypertrophy were recruited in the study, which was carried out at tertiary level center from May 2014 - May 2016.

Results: The results of study showed that both following septoplasty \& TRS, post-operative mean NOSE score improvement were highly significant but among these two groups, patient who underwent septoplasty along with TRS had better result. ( $p<0.05)$ Study Limitations- longer follow up, larger sample size.
\end{abstract}

Keywords: deviated nasal, deviated nasal septum, inferior turbinate hypertrophy, septoplasty, turbinate reduction, submucosal diathermy, NOSE Scale.

\section{Introduction}

Nasal obstruction is a common presenting symptom which otolaryngologists encounter in daily clinical practice. It affects $9.5-15 \%$ of general population. There can be many etiologies for chronic nasal obstruction like deviated nasal septum with or without turbinate hypertrophy, only turbinate hypertrophy, allergic rhinitis, vasomotor rhinitis, infective rhinitis, nasal polyposis, granulomatous disease or nasal tumours, adenoid hypertrophy.

Among these etiologies for nasal obstruction, the most commonest is deviated nasal septum.

Deviated nasal septum towards one side is often associated with overgrowth of inferior turbinate, which occupies expansive space on contralateral nasal cavity. It is assumed that this counter balanced mechanism characterised by compensatory hypertrophy originates to protect the more patent nasal side from excess airflow with its drying and crusting effects. Beside septal deviation, enlarged turbinates are the second most frequent cause of obstruction to nasal breathing. Chronic obstruction of nasal breathing can interfere with social and business activities and can thus considerably compromise quality of life. The inferior turbinate (concha nasalis inferior) is the largest of all turbinates. Compensatory hypertrophy is a frequent "pathological" entity and in connection with a c-shaped deviation of the nasal septum always appears on the side of the broadest main nasal cavity.

A surgical reduction of the turbinate should only be indicated if a three-month conservative therapy has not had any subjective and objective (active anterior rhinomanometry, acoustic rhinometry) success. The main aim of turbinate surgery has to be the preservation of a well-functioning mucosa membrane, whilst at the same time creating a sufficiently large air space to ensure the humidification and purification of air and the maintenance of a physiological airway resistance.

\section{The different surgical techniques are}

- Lateroposition,Resection, Coagulation

Types Of Resectioning Procedures Consist Of Total Tubinectomy( Regarded As The Most Radical Surgical Measure On The Inferior Turbinate),,Partial Turbinectomy(With A Partial Turbinectomy, Mucosal Membrane And Bones Are Resected In The Front Third Of The Turbinate.),Submucosalturbinectomy,Inferior(Anterior)Turbinoplasty.

Coagulating Procedure Include Submucosal Diathermia, Electocoagulation Of The Turbinate Mucosa,Cryotherapy, Argon Plasma Coagulation, Radiofrequency Therapy And Laser Surgical Procedures

\section{Materials And Methods}

This study was carried out in ENT OPD at MGM Hospital, Aurangabad during the time period of May 2014May 2016. All patients above 17 years of age, and below 50 years with history of nasal obstruction for at least 3 months and clinically diagnosed to have deviated nasal septum with inferior turbinate hypertrophy. Patients with 
nasal obstruction diagnosed to have vasomotor rhinitis; infective rhinitis; nasal polyps; granulomatous disease; nasal tumors were not included in the study.

30 patients with septal deviation and contralateral inferior turbinate hypertrophy were recruited in the study. Detailed history, clinical examination and diagnostic nasal endoscopy was done. Patients were asked to fill questionnaires relating to severity of their symptoms using Nasal Obstruction Symptom Evaluation(NOSE) scale. Patients were then be randomly divided into two groups. In group A, only septoplasty was performed. In group B, reduction of inferior turbinate by submucosal coagulation cautery was performed to treat hypertrophied inferior turbinate together with septoplasty. Post-operative patient's symptoms were again evaluated using Nasal Obstruction Symptom Evaluation Scale (NOSE) at 1,3 and 6 months. Nasal airway was evaluated at 1, 3 and 6 months post surgery with nasal endoscope and compared with preoperative findings.

Nose Score - Used for subjective measurement of symptoms-

Scores taken pre-operatively, 1 month post-operatively, 3 months post- operatively, 6 months post-operatively. Total Score= Q1+Q2+Q3+Q4+Q5x100

Total score from 0 to 100.

$0-\quad$ minimum severity

100- maximum severity.

Change in pre to post operative at $1,3 \& 6$ months is compared between group A- Septoplasty only \& group BSeptoplasty + TRS. Each group consists of 15 patients.

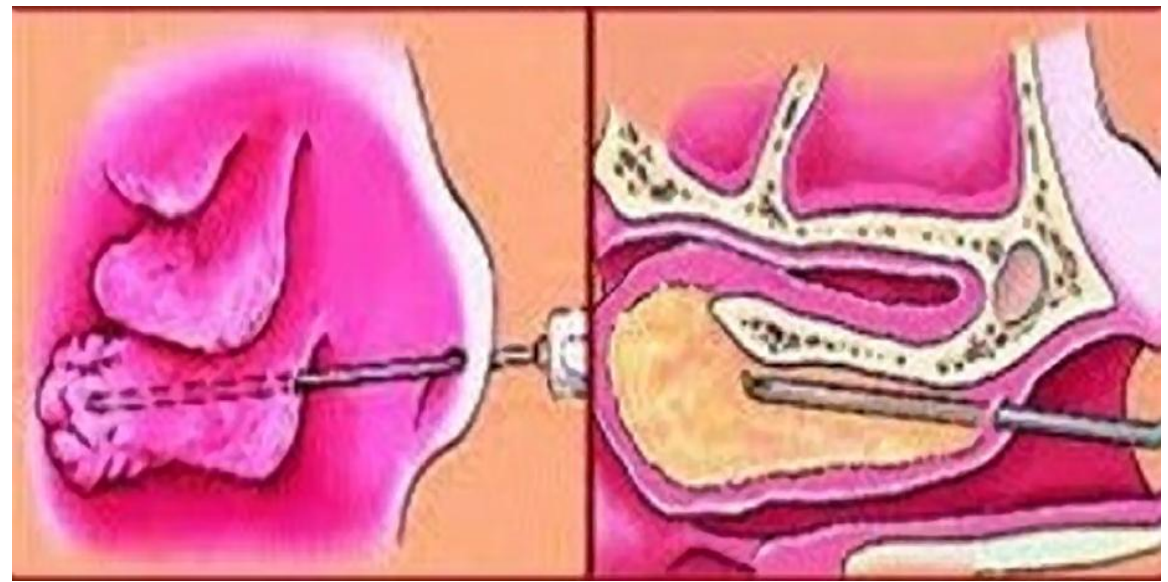

Figure - 1 : Unipolar cautery probe insertion technique

III. Results

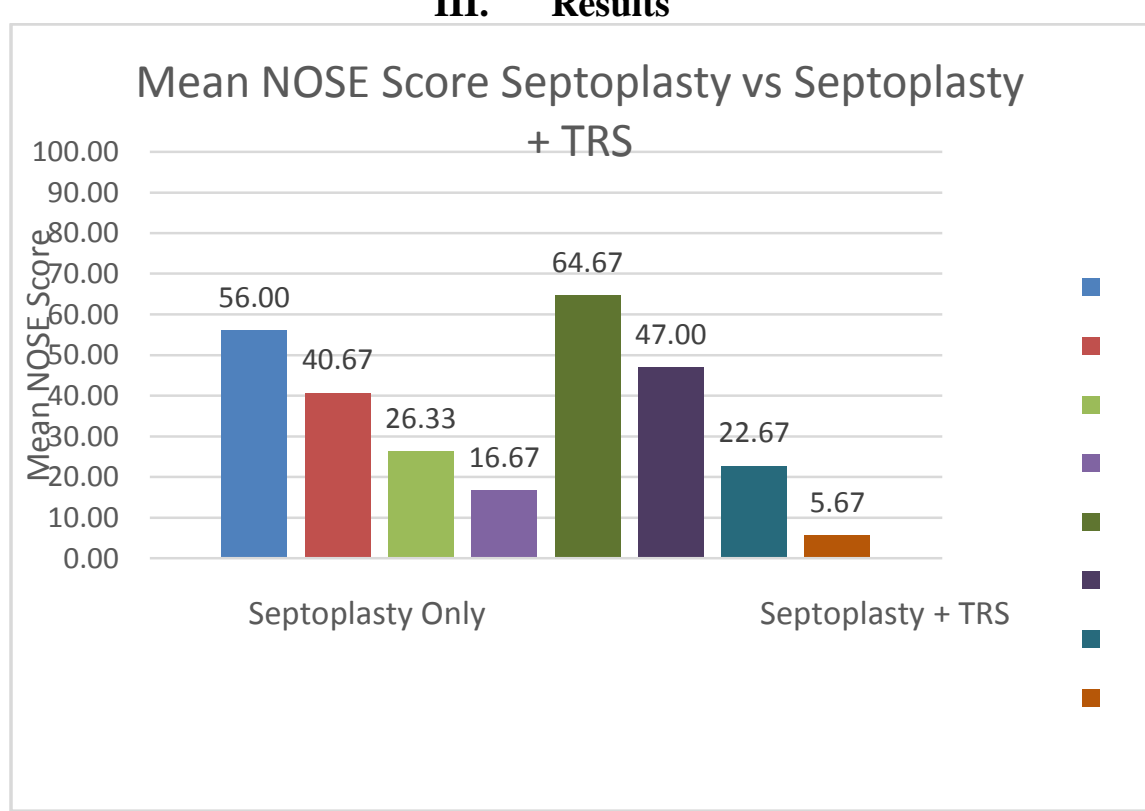

Figure 2 - Mean NOSE Score- Septoplasty vs Septoplasty + TRS 


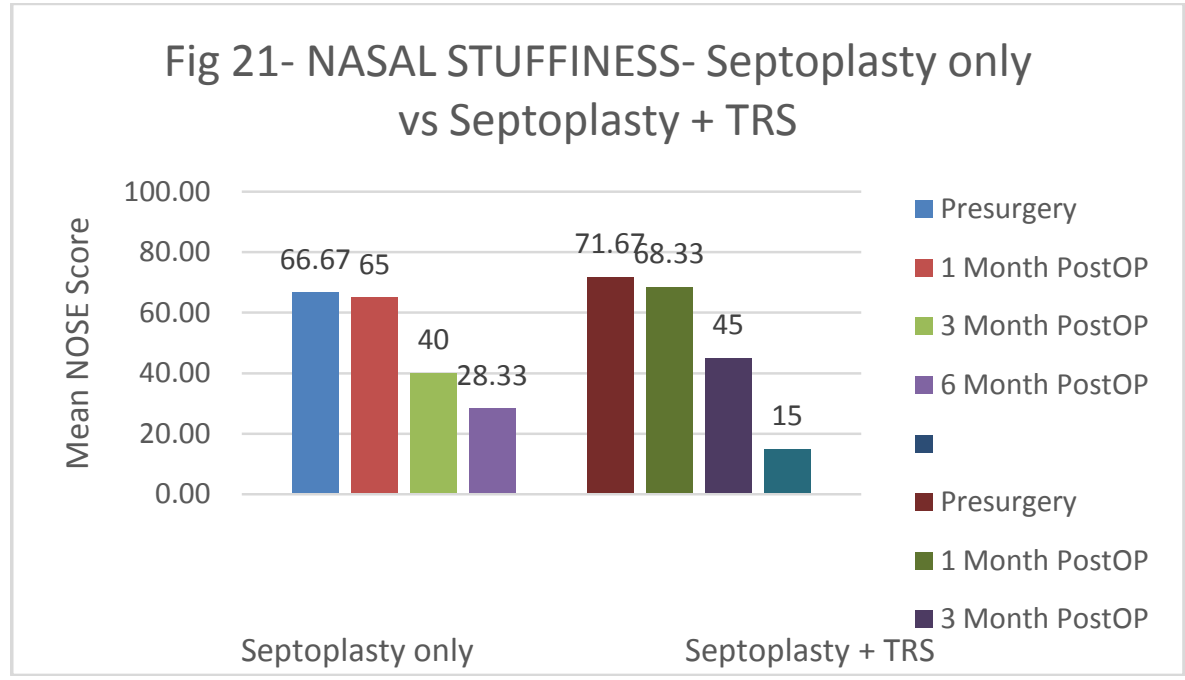

Figure 3 - Nasal Stuffiness- Septoplasty Only Vs Septoplasty + Trs

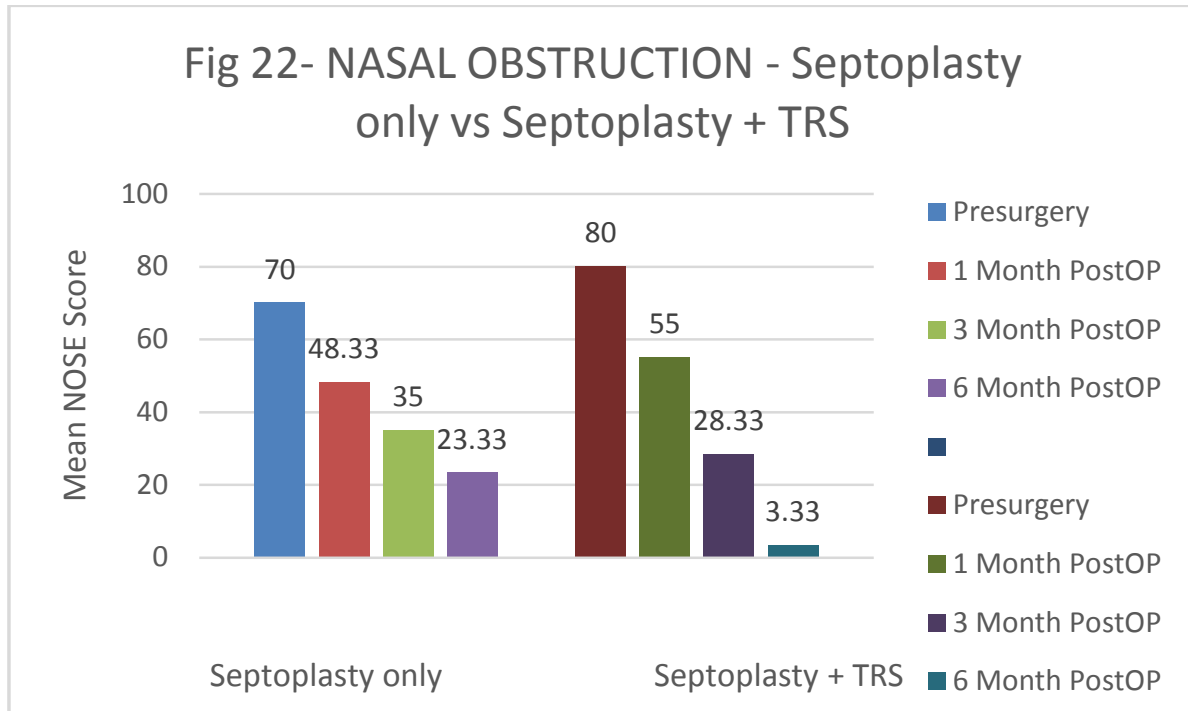

Figure 4 - nasal obstruction - septoplasty only vs septoplasty + trs

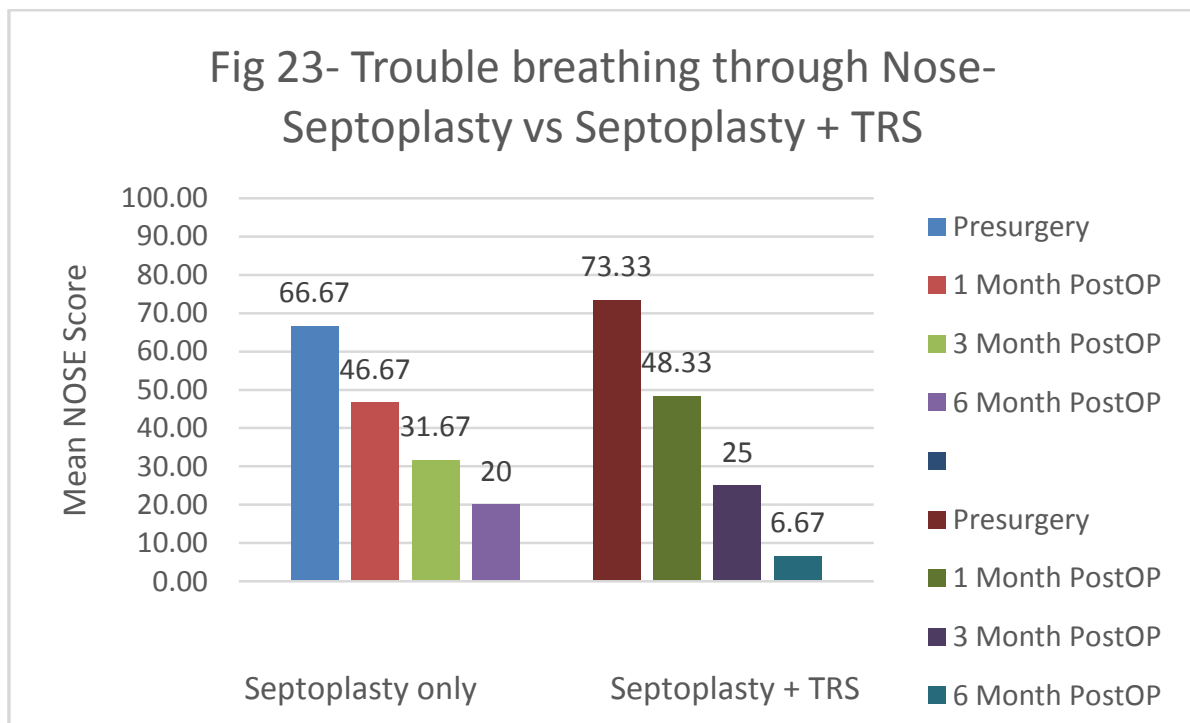

Figure 5 - Trouble breathing through Nose- Septoplasty vs Septoplasty + TRS 


\section{Discussion}

Nasal obstruction is one of the most common complaints by patients which an otolaryngologist encounters in day to day practice. It affects $9.5-15 \%$ of general population ${ }^{1}$. Nasal septum deviation \& associated turbinate hypertrophy is one of its most frequent causes.

The present study was carried out to know whether reduction of hypertrophied Inferior turbinate in addition to Septoplasty improves outcome of nasal obstruction in patients with deviated nasal septum with inferior turbinate hypertrophy, to know whether hypertrophied Inferior turbinate contributes to nasal obstruction in patients with deviated nasal septum \& to know the effectiveness of reduction of hypertrophied turbinate together with septoplasty for the treatment of nasal obstruction in patients with deviated nasal septum.In this study NOSE score was used for subjective evaluation of patient's quality of life.The present study showed highly significant result for post-operative improvement for both septoplasty \& septoplasty + turbinate reduction. According to NOSE score, patients who underwent TRS with septoplasty had overall greater symptomatic relief on follow up compared to those who underwent septoplasty alone. In both groups, symptomatic improvement was gradual over the period of 6 months. Compared to the septoplasty group, patients who underwent septoplasty + TRS showed statistically significant symptomatic improvement at 6 months follow up.Our study concludes that TRS in addition to septoplasty offers greater symptomatic relief compared to those undergoing septoplasty alone.

\section{Conclusions}

The results of study showed that hypertrophied inferior turbinate need to be addressed in chronic cases of nasal obstruction with deviated nasal septum \& contralateral inferior turbinate hypertrophy. And in these patient TRS should be done in addition to septoplasty.

- Reduction of hypertrophied Inferior turbinate in addition to Septoplasty improves outcome of nasal obstruction \& results in significant improvement in disease-specific quality of life in patients with deviated nasal septum with inferior turbinate hypertrophy,

- NOSE score can be used as a subjective tool for symptomatic measurement of patients with nasal obstruction and in assessing the efficacy of treatment addressing nasal obstruction.

\section{References}

[1]. Akerlund A, Millqvist E, Oberg D, Bende M. Prevalence of upper and lower airway symptoms: the Skovde population-based study. Acta Otolaryngol. 2006;126:483-88

[2]. Gleeson M, Browning GG, Burton MJ, Clarke R, Hibbert J, Jones NS, Lund VJ,editors. Scott-Brown's otorhinolaryngology, head and neck surgery. 7th ed. London:Hodder Arnold. 2008 p: 1315-43, 1356-77, 1386-90, 1439-44, 1549 -57, 1569-1581.

[3]. Brain D. The nasal septum. In: Mackay IS, Bull TR, eds.Scott-Brown's Otolaryngology, ed 5. London: Butterworth\& Co. Ltd. Rhinology, vol 4, 1987:154-179.

[4]. Gilead Berger, MD; Ilan Hammel, DSc; Rachel Berger, BA; Shabtai Avraham, MD; Dov Ophir, MD: Histopathology of the inferior turbinate with compensatory hypertrophy in patients with deviated nasal septum, Laryngoscope 110:2100-2105.

[5]. Kim DH, Park HY, Kim HS et al. Effect of septoplasty on inferior turbinate hypertrophy. Arch Otolaryngol Head Neck Surg 2008; $134: 419-423$.

[6]. Egeli E, Demerci L, Yazycy B, Harputlouglu U. Evaluation of the inferior turbinate in patients with deviated nasal septum by using computed tomography. Laryngoscope 2004; 114: 113-117.

[7]. Fairbanks DNF, Kaliner M. Nonallergic rhinitis and infection. In: Cummings CW, Fredrickson JM, Harker AL,Krause CJ, Richardson MA, Schuller DE, eds. Otolaryngology Head and Neck Surgery.vol 2, ed 3. St. Louis: Mosby,1998:910-920.

[8]. Richardson J. Turbinate treatment in vasomotor rhinitis. Laryngoscope 1985; $58: 834-847$.

[9]. Jones AS, Wight RG, Kabil Y, Buckingham E. Predicting the outcome of submucosal diathermy to the inferior turbinates. Clin Otolaryngol 1989; 14:41-44.

[10]. Stewart et al. Outcome after nasal septoplasty: Results from the nasal obstruction septoplasty effectiveness (Nose) study, Otolaryngology and Head and Neck surgery,Mar2004; Vol (130) No.3:283-290. 